\title{
Interacting effects of climate and agriculture on fluvial DOM in temperate and subtropical catchments
}

\author{
D. Graeber ${ }^{1}$, G. Goyenola ${ }^{1,2}$, M. Meerhoff ${ }^{2}$, E. Zwirnmann ${ }^{3}$, N. B. Ovesen ${ }^{1}$, M. Glendell ${ }^{4}$, J. Gelbrecht ${ }^{3}$, \\ F. Teixeira de Mello $^{2}$, I. González-Bergonzoni ${ }^{1,2,5}$, E. Jeppesen ${ }^{1,5}$, and B. Kronvang ${ }^{1}$ \\ ${ }^{1}$ Department of Bioscience, Aarhus University, Aarhus, Denmark \\ ${ }^{2}$ Centro Universitario Regional Este, Facultad de Ciencias, Universidad de la Repũblica, Maldonado, Uruguay \\ ${ }^{3}$ Chemical Analytics and Biogeochemistry, Leibniz-Institute of Freshwater Ecology and Inland Fisheries, Berlin, Germany \\ ${ }^{4}$ Geography, College of Life and Environmental Sciences, University of Exeter, Exeter, UK \\ ${ }^{5}$ Sino-Danish Centre for Education and Research, Beijing, China \\ Correspondence to: D. Graeber (dgr@dmu.dk)
}

Received: 29 November 2014 - Published in Hydrol. Earth Syst. Sci. Discuss.: 7 January 2015

Revised: 26 April 2015 - Accepted: 28 April 2015 - Published: 20 May 2015

\begin{abstract}
Dissolved organic matter (DOM) is an important factor in aquatic ecosystems, which is involved in a large variety of biogeochemical and ecological processes, and recent literature suggests that it could be strongly affected by agriculture in different climates. Based on novel monitoring techniques, we investigated the interaction of climate and agriculture effects on DOM quantity and quality. To examine this, we took water samples over 2 years in two paired intensive and extensive farming catchments in each of Denmark (temperate climate) and Uruguay (subtropical climate). We measured dissolved organic carbon (DOC) and nitrogen (DON) concentrations and DOC and DON molecular fractions with size-exclusion chromatography. Moreover, we characterized DOM quality with absorbance and fluorescence measurements, as well as parallel factor analysis (PARAFAC). We also calculated the DOC and DON loads based on daily discharge measurements, as well as measured precipitation and air temperature. The fluvial DOM in the catchments in Uruguay was characterized by higher temporal variability of DOC and DON loads which were clearly to a higher temporal variability of precipitation and a DOM composition with rather plant-like character relative to the Danish catchments. Moreover, we found a consistently higher temporal variability of DOC and DON loads in the intensive farming catchments than in the extensive farming catchments, with highest temporal variability in the Uruguayan intensive farming catchment. Furthermore, the composition of DOM exported from the intensive farming catchments was consis-
\end{abstract}

tently complex and always related to microbial processing in both Denmark and Uruguay. This was indicated by low $\mathrm{C}: \mathrm{N}$ ratios, several spectroscopic DOM composition indices and PARAFAC fluorescence components. We propose that the consistent effect of intensive farming on DOM composition and the temporal variability of DOC and DON loads is related to similarities in the management of agriculture, which may have widescale implications for fluvial DOM composition, as well as related ecological processes and biogeochemical cycles.

\section{Introduction}

Dissolved organic matter (DOM) is an important biogeochemical component in aquatic ecosystems, which is involved in a large variety of ecological processes (Prairie, 2008; Fellman et al., 2010; Berman and Bronk, 2003). Amongst other elements, DOM contains carbon (dissolved organic carbon, DOC) and nitrogen (dissolved organic nitrogen, DON): DOC can be an important source for aquatic microbial respiration and DON can be an important source of nitrogen to aquatic ecosystems (Berman and Bronk, 2003; Prairie, 2008). Therefore, changes in DOC and DON concentrations and loads may affect ecosystem functions of freshwater ecosystems (Stanley et al., 2012; van Kessel et al., 2009). 
Climatic, soil and topographic variables are usually strong predictors of DOM in streams, as these often control the terrestrial storage of organic matter and the hydrological connectivity between catchments and streams (Stanley et al., 2012). For example, a large portion of the global variability of DOC concentrations is explained by soil $\mathrm{C}: \mathrm{N}$ ratios (Aitkenhead and McDowell, 2000) and annual runoff predicts catchment DOC export across climates (Mulholland, 1997). However, the effects of landscape and climate are strongly altered by land use, which has a range of consequences for vegetation cover, catchment hydrology, soil properties and nutrient export (Stanley et al., 2012). Recent studies in northern temperate climate have found that the intensity of agricultural management strongly affects the molecular composition and seasonality of fluvial DOM (e.g. Dalzell et al., 2007; Williams et al., 2010; Graeber et al., 2012b; Stanley et al., 2012). However, it is still unclear whether similar effects of agriculture on fluvial DOM are also found in other climates.

Contradictory effects of agriculture on DOM quantity in terms of DOC concentrations have been reported (Stanley et al., 2012; Graeber et al., 2012b). These different effects could be a result of differences in catchment size, climate, land use history, sampling strategy and agricultural management (Stanley et al., 2012). We propose that in small catchments, intensive agriculture results in increased DOC concentrations and loads in the draining freshwater systems, since increased microbial activity and anthropogenic soil disturbance by tilling can release previously inert DOC from the soil matrix (Balesdent et al., 2000; Sickman et al., 2010; Ewing et al., 2006). However, most studies to date were undertaken in larger catchments or in catchments with a mix of catchment sizes, where this effect may be obscured by in-stream processing of agricultural DOC (Graeber et al., 2012b).

In contrast to DOC concentration, the temporal variability of DOC loads from catchments with intensive agriculture to temperate freshwater systems was found to be consistently high due to discharge fluctuations during short-term, high-discharge events (Dalzell et al., 2007; Royer and David, 2005; Graeber et al., 2012b). Thus, it is likely that intensive agriculture will have a similar effect on the temporal variability of DOC loads in other climates.

Similarly to DOC, contradictory effects of agriculture on DON concentrations have been found (Stanley and Maxted, 2008; van Kessel et al., 2009; Siemens and Kaupenjohann, 2002; Williams et al., 2005; Willett et al., 2004; Petrone, 2010), largely due to the same factors as for DOC. However, all but one study (Heinz et al., 2015) of DON in agricultural environments to date have been based on indirect calculation of DON as the difference between total dissolved nitrogen and dissolved inorganic nitrogen, potentially leading to high uncertainty in the calculated DON concentrations (Lee and Westerhoff, 2005; Graeber et al., 2012a). Therefore, sizeexclusion chromatography (SEC) represents a novel, direct measurement alternative to assess DOC and DON concentrations and molecular composition that is sufficiently fast to be used in monitoring programmes (Graeber et al., 2012a; Huber et al., 2011). By using this novel approach it would be possible to test the existing opinions on the role of agriculture for DON export. We propose that the same factors as for DOC (higher microbial activity, soil disturbance) should affect DON, thus increasing the DON concentrations in the export from small, intensive agricultural catchments.

Fluorescence and absorbance spectroscopy have been the methods of choice for the assessment of DOM composition to date. These measurements allow a detailed understanding of DOM composition (e.g. Fellman et al., 2010; Helms et al., 2008), especially when combined to parallel factor analysis (PARAFAC, Murphy et al., 2013; Stubbins et al., 2014). Spectroscopic measurements of DOM composition revealed that DOM from catchments with intensive agriculture is usually dominated by complex, humic fluorophores, is characterized by high humification and low contribution of protein-like fluorophores, and is likely to be released from microbial sources (Wilson and Xenopoulos, 2009; Williams et al., 2010; Graeber et al., 2012b; Fellman et al., 2011; Heinz et al., 2015). Moreover, existing time series indicate a stable composition of DOM exported from agricultural catchments across seasons, most likely linked to stable catchment DOM sources (Graeber et al., 2012b; Heinz et al., 2015). However, these studies focused on agricultural catchments in temperate climate and time series of spectroscopic DOM composition were limited to one year or less. Therefore, a more complete understanding of the effects of agriculture on DOM composition and its temporal variability in different climates over extended time periods is required. Moreover, a combination of techniques, including spectroscopic measurements with other analytical methods (e.g. with SEC) will allow a more accurate interpretation of spectroscopic measurements and a better understanding of DOM composition (Stubbins et al., 2014).

The combination of SEC and spectroscopic measurements constitutes a novel monitoring technique, which will allow greater insight into the effects of agriculture on DOM in freshwater systems. We used this technique to compare the quantity and variability of DOC and DON concentrations, loads and DOM quality for catchments with extensive and intensive farming in temperate (Denmark) and subtropical (Uruguay) climates. Intensive farming was characterized by intensive crop production with or without tile drainage, depending on the soil, whereas extensive farming was characterized by non-fertilized, extensively used pastures. We hypothesized that (i) the higher and more variable precipitation in Uruguay will result in higher and more variable DOC and DON loads in streams, (ii) the warmer climate in Uruguay will strongly affect DOM quality through higher microbial activity in soils and streams, (iii) within a similar climate, the higher anthropogenic soil disturbance and higher variability of runoff from intensive farming catchments results in 
higher DOC and DON concentrations and higher temporal variability of DOC and DON loads, and that (iv) DOM quality will be similarly affected by intensive farming relative to extensive farming across climates, due to similar agricultural management practices (fertilization, soil tillage).

\section{Methods}

\subsection{Study sites}

Two catchments in Denmark (temperate climate) and two catchments in Uruguay (subtropical climate) were chosen for this study. The catchments were characterized by either pasture (extensive farming) or arable farming (intensive farming, Table 1). The Danish intensive farming catchment was characterized by subsurface tile drainage. Both the extensive catchment in Denmark and the extensive catchment in Uruguay contained a large area of the catchment with extensive land use. Since no larger forests exist naturally in Uruguay, extensively used pasture is the most natural land use in Uruguay. Please see Goyenola et al. (2015) for further details on the land use in the catchments.

In Denmark, the soils in the intensive farming catchment were dominated by gleyic Luvisols, while in the extensive farming catchment the soils were dominated by Haplic Luvisols (World Reference Soil Database classification, European Commission and European Soil Bureau Network, 2004). In Uruguay, the intensive farming catchment was dominated by Luvic Phaeozem and Eutric Vertisols, while the Uruguayan extensive farming catchment was dominated by Eutric Regosols (SOTERLAC database, ISRIC foundation, http://www.isric.org).

\subsection{Field sampling and laboratory measurements}

In Uruguay, precipitation and air temperature were measured at the sample sites with instruments (Rain-o-matic precipitation sensor, Pronamic, Ringkøbing, Denmark, November 2009-September 2012), while in Denmark data were extracted from country-wide data set provided by the Danish Meteorological Institute (DMI, February 2010-May 2012). Both Danish catchments had the same temperature values, since they were in the same temperature grid of the DMI data set. In both countries, discharge was measured every $10 \mathrm{~min}$ by a pressure transducer in combination with a depthdischarge relationship (Hymer software, version 3.0.11, Orbicon, Roskilde, Denmark) and summed up to daily values for further analysis. Annual precipitation could be compared between the catchments only for 2011, since only for this year do simultaneous, continuous precipitation measurements do exist for all four catchments.

Water samples were collected on average every fortnight from 2 April 2010 to 14 March 2012 from the outflows of the two catchments in Denmark and from 2 June 2010 to 29 May 2012 from the outflows of the two catchments
Table 1. Names, position of the sampled catchment (WGS 84) and farming type of the investigated catchments. DK: Denmark, UY: Uruguay, extensive: extensive farming, intensive: intensive farming.

\begin{tabular}{|c|c|c|c|}
\hline Catchment & Coordinates & $\begin{array}{l}\text { Catchment } \\
\text { area }\left(\mathrm{km}^{2}\right)\end{array}$ & $\begin{array}{l}\text { Land use, percentages } \\
\text { of catchment area }(\%)\end{array}$ \\
\hline DK, extensive & $\begin{array}{l}56^{\circ} 17^{\prime} 2^{\prime \prime} \mathrm{N} \\
9^{\circ} 53^{\prime} 51^{\prime \prime} \mathrm{E}\end{array}$ & 7.4 & $\begin{array}{l}\text { Forest (59); arable } \\
\text { farming (29); } \\
\text { pasture/meadow } \\
(7) \text {; other (5) }\end{array}$ \\
\hline DK, intensive & $\begin{array}{l}56^{\circ} 13^{\prime} 29^{\prime \prime} \mathrm{N} \\
9^{\circ} 48^{\prime} 41^{\prime \prime} \mathrm{E}\end{array}$ & 11.8 & $\begin{array}{l}\text { Arable farming (92); } \\
\text { forest (2); urban (1); } \\
\text { other (5) }\end{array}$ \\
\hline UY, extensive & $\begin{array}{l}33^{\circ} 49^{\prime} 31^{\prime \prime} \mathrm{S} \\
56^{\circ} 16^{\prime} 55^{\prime \prime} \mathrm{W}\end{array}$ & 18.8 & $\begin{array}{l}\text { Extensive pasture } \\
(\sim 70) \text {; arable farming } \\
(\sim 30)\end{array}$ \\
\hline UY, intensive & $\begin{array}{l}33^{\circ} 54^{\prime} 13^{\prime \prime} \mathrm{S} \\
56^{\circ} 00^{\prime} 23^{\prime \prime} \mathrm{W}\end{array}$ & 8.4 & $\begin{array}{l}\text { Arable farming and } \\
\text { dairy farms }(90) ; \\
\text { extensive pasture (7); } \\
\text { urban (3) }\end{array}$ \\
\hline
\end{tabular}

in Uruguay. At each sampling date, a water sample was taken, filtered with pre-rinsed (1 L Milli-Q water) GF/C filters (Whatman, GE Healthcare Europe, Brøndby, Denmark) in Uruguay or $0.45 \mu \mathrm{m}$ filters (Frisenette, MontaMil, mixed cellulose ester, Knebel, Denmark) in Denmark and acidified to $\mathrm{pH} \sim 2$ with hydrochloric acid to allow stabilization of DOM during storage. Subsequently, the samples were frozen for later analysis of DOM concentration and molecular composition. The samples were acidified and frozen, since they had to be sent to a laboratory in Germany to be measured between February and April 2012 and in October 2012, which resulted in long storage times, for which filtration and cooling is not sufficient (Hudson et al., 2009).

Before the laboratory measurements, all samples were brought to the same target $\mathrm{pH}$ of $7.5 \pm 0.5$. A final mean $\mathrm{pH}$ of $7.52(\mathrm{SD}=0.16, \min =7.2, \max =7.9)$ was reached by neutralization of the samples with sodium hydroxide. Changes in DOM fluorescence by acidification can be fully reversed by neutralization of the samples with no effects of acidification on fluorescence measurements (PatelSorrentino et al., 2002) or SEC measurements (Huber et al., 2011) of DOM composition expected in the range of the final $\mathrm{pH}$ values. Moreover, the Uruguayan samples have been refiltered with pre-rinsed (with $150 \mathrm{~mL}$ Milli-Q water) $0.45 \mu \mathrm{m}$ filters (Minisart, cellulose-acetate, Sartorius, Göttingen, Germany) to correspond with the Danish samples. However, according to a recent study, different filter sizes or types do not strongly affect measurements of DOM composition (Nimptsch et al., 2014). Moreover, no residue DOM from acidification, neutralization and additional filtration could be found when checking with filter and acidification blanks.

Absorbance was measured on a UV-2401 UV/Vis spectrophotometer (Shimadzu, Duisburg, Germany), using $1 \mathrm{~cm}$ 
quartz glass cuvettes to correspond with fluorescence measurements, as well as with $5 \mathrm{~cm}$ quartz glass cuvettes for calculation of absorbance-based indices. Absorbance was measured between 190-800 $\mathrm{nm}$. Before calculating the absorbance-based indices, the mean absorbance between 600-800 nm was subtracted from single absorbance values to correct for instrument baseline offset (Green and Blough, 1994).

Excitation was measured between $240-450 \mathrm{~nm}$ in $5 \mathrm{~nm}$ steps and emission was measured between $300-600 \mathrm{~nm}$ in $2 \mathrm{~nm}$ steps. Both were measured with a bandwidth of $5 \mathrm{~nm}$ and a speed of $1000 \mathrm{~nm} \mathrm{~s}^{-1}$, using a LS-50B fluorescence spectrometer (Perkin-Elmer, Rodgau, Germany). Samples exhibiting an absorbance $>0.3 \mathrm{~cm}^{-1}$ were diluted to a lower fluorescence to allow precise correction of the inner-filter effect (Ohno, 2002), although a recent study deemed such dilution unnecessary (Kothawala et al., 2013). All samples were measured at room temperature.

Size-exclusion chromatography (SEC) was used for the analysis of the molecular-size composition of DOC and DON. The sum of DOC and DON molecular-size fractions represents DOC and DON concentrations. The system used in this study was developed by Huber et al. (2011) and the direct measurement of DON with high accuracy was demonstrated in freshwater systems for this SEC system (see Fig. A1 in the Appendix for a typical chromatogram from SEC, Graeber et al., 2012a). The SEC system uses a combination of ultraviolet- (UV) and infraredorganic carbon detection and UV-organic nitrogen detection (Graeber et al., 2012a; Huber et al., 2011). This procedure detects non-humic high molecular weight substances (carbon $=\mathrm{HMWS}_{\mathrm{C}}$, nitrogen $=\mathrm{HMWS}_{\mathrm{N}}$ ) of hydrophilic character (polysaccharides, proteins, amino sugars), humic-like substances (carbon $=\mathrm{HS}_{\mathrm{C}}$, nitrogen $=\mathrm{HS}_{\mathrm{N}}$ ) with higher aromaticity based on UV measurements at $254 \mathrm{~nm}$, and lowmolecular weight acids and circumneutral substances which were combined as low-molecular weight substances in this study (carbon $=\mathrm{LMWS}_{\mathrm{C}}$, Graeber et al., 2012a; Huber et al., 2011). The LMWS refer to neutral, hydrophilic to amphiphillic substances (alcoholes, aldehydes, ketones, sugars, amino acids, Huber et al., 2011). Nitrogen could not be determined for the LMWS fraction, since it cannot accurately be separated from nitrate (Huber et al., 2011). Unlike wastewaters (Chon et al., 2013) this fraction contains very little DON and therefore does not contribute significantly to DON determination in freshwaters, when using SEC (Graeber et al., 2012a). The quantification limit of SEC for DOC and DON in each fraction was $0.01 \mathrm{mg} \mathrm{L}^{-1}$ and values below the quantification limit were set to $0.005 \mathrm{mg} \mathrm{L}^{-1}$. Specific UV absorbance at $254 \mathrm{~nm}$ was determined for the $\mathrm{HS}$ fraction $\left(\mathrm{SUVA}_{\mathrm{HS}}\right)$ and for all DOM fractions $\left(\mathrm{SUVA}_{\text {bulk }}\right)$ as $\mathrm{L} \mathrm{mg}^{-1} \mathrm{~m}^{-1}$. SUVA is positively correlated to the aromaticity of DOM (Weishaar et al., 2003).

\subsection{Treatment of spectroscopic and chromatographic data}

The drEEM toolbox was used to standardize all measured excitation-emission matrices (EEMs, Murphy et al., 2013): spectral correction was based on instrument-specific values for excitation and using a correction kit for emission (BAM fluorescence calibration kit, Pfeifer et al., 2006). Inner-filter effect correction was based on absorbance measurements and using the processing proposed in the drEEM toolbox, which accurately removes the inner-filter effect (Kothawala et al., 2013). All samples were Raman normalized, based on measurements of the Raman peak at $350 \mathrm{~nm}$ and according to the processing used in the drEEM toolbox and described in Murphy et al. (2013). The resulting Raman units compare well between instruments and studies (Lawaetz and Stedmon, 2009).

Using the drEEM toolbox, a parallel factor analysis (PARAFAC) model with four components (C1-C4) was validated using residual and sum-of-squared-error investigation, as well as split-half validation (see Fig. B1 in the Appendix for plots of the split-half validated model) and random initialization (Murphy et al., 2013). For interpretation, the PARAFAC components were compared with data sets in the OpenFluor database (http://www.openfluor.org, Murphy et al., 2014) and with published literature.

Based on fluorescence measurements, three indices were calculated: (i) the fluorescence index, which indicates more a microbial $(\sim 1.9)$ or a terrestrial higher plant $(\sim 1.4)$ origin of the DOM (Cory and McKnight, 2005), (ii) the freshness index, with values $>1$ representing DOM recently released from microbial organisms, and values of $0.6-0.8$ representing older or plant DOM (Parlanti et al., 2000) and (iii) the humification index for which higher values indicate more humified DOM (Ohno and Bro, 2006). Based on absorbance measurements, four indices were calculated: (i) $E_{2}: E_{3}$, which is negatively correlated to the relative size of the DOM molecules (Helms et al., 2008; Peuravuori and Pihlaja, 2004), and three absorbance slope indices (Helms et al., 2008): (ii) $S_{275-295}$ and $S_{\mathrm{R}}$, which are positively related to irradiation and decrease during incubation experiments and (iii) $S_{350-400}$, which is negatively related to irradiation and increases during incubation experiments. Moreover, all three slope indices are negatively related to the molecular weight of DOM (Helms et al., 2008).

Instead of using absolute concentrations or Raman units, the fraction concentrations from SEC $\left(\mathrm{HMWS}_{\mathrm{C}}, \mathrm{HMWS}_{\mathrm{N}}\right.$, $\mathrm{HS}_{\mathrm{C}}, \mathrm{HS}_{\mathrm{N}}, \mathrm{LMWS}_{\mathrm{C}}$ ) and the PARAFAC components (C1$\mathrm{C} 4)$ were converted to percentages, either as a proportion of the total concentration of SEC fractions or of the total fluorescence of the sample (PARAFAC), in order to investigate changes in DOM composition independently from changes in DOM quantity. For both DOC and DON, all SEC fractions were summed to estimate total DOM quantity; hereinafter, 
these sums will be referred to as DOC and DON concentrations.

Based on SEC, molar $\mathrm{C}: \mathrm{N}$ ratios were calculated for $\mathrm{HS}$ $\left(\mathrm{C}: \mathrm{N}_{\mathrm{HS}}\right)$ and all SEC fractions $\left(\mathrm{C}: \mathrm{N}_{\text {bulk }}\right)$. Molar $\mathrm{C}: \mathrm{N}$ ratios were not calculated for HMWS, since HMWS nitrogen concentrations were partly below the quantification limit, which resulted in unreliable $\mathrm{C}: \mathrm{N}$ ratios.

\subsection{Calculation of DOC and DON daily and annual loads}

DOC and DON concentrations were linearly interpolated between sampling occasions and loads were calculated for each day with load calculated as discharge times interpolated DOC or DON concentration (Kauppila and Koskiaho, 2003). To calculate the annual load, all daily loads of 1 year were summed up and normalized by the catchment area (Table 1). This approach was compared to other potential approaches in Kauppila and Koskiaho (2003) and was found to provide the most reliable estimates of nutrient loads from discontinuous concentration data. However, since considerable bias of the interpolated data is possible and cannot be ruled out, we only discuss strong patterns related to the calculated DOC and DON loads. Annual loads could only be compared between all study catchments in 2011, as simultaneous continuous time series of DOC concentration, DON concentration and discharge were only available for all catchments during this period.

\subsection{Statistical analyses}

All statistical analyses were conducted in R ( $\mathrm{R}$ Core Team, 2015). All following statistics assume independent temporal replicates, as neither DOC and DON concentrations or DOM composition variables were temporally autocorrelated in any of the catchments (acf function R Core Team, 2015). All permutation tests and resampling procedures were conducted with 9999 iterations.

To assess the effects of country and farming type within countries on DOC and DON concentrations, permutative one-way tests were used (oneway_test function, coin package, Hothorn et al., 2006). Moreover, to assess pairwise differences between the sampled catchments, Nemenyi tests were used (adapted oneway_test function, coin package, Hollander et al., 2013). To investigate whether DOC concentration was correlated with discharge, a Spearman rank correlation was used for each of the catchments independently (cor.test function, R Core Team, 2015).

To assess changes in temporal variability of precipitation, discharge, DOC loads and DON loads between countries and farming types within the countries, Levene's test based on medians (leveneTest function, car package, Fox and Weisberg, 2011) was used. To assess whether the temporal variability of DOC and DON loads was dependent on discharge or on DOC and DON concentrations, a sensitivity analy- sis of the load calculations was conducted for each catchment separately. This was done as described in Pouillot and Delignette-Muller (2010), but based on bootstrap resampling of the DOC and DON concentrations and discharge values. The output of this analysis is Spearman's $\rho$ and here, a high Spearman's $\rho$ indicates a high sensitivity of the temporal variability of the loads on the temporal variability of the respective input variable (either concentration or discharge) and a low Spearman's $\rho$ indicates a low sensitivity.

To investigate the changes of DOM composition with country and type of farming and to examine the relationships between DOM composition variables, a principal component analysis was conducted for all 20 variables of DOM composition: $\mathrm{HMWS}_{\mathrm{C}}, \mathrm{HMWS}_{\mathrm{N}}, \mathrm{HS}_{\mathrm{C}}, \mathrm{HS}_{\mathrm{N}}, \mathrm{LMWS}_{\mathrm{C}}$, SUVA $_{H S}, S_{U V A}$ bulk $, C: \mathrm{N}_{\text {bulk }}, \mathrm{C}: \mathrm{N}_{\mathrm{HS}}, \mathrm{C} 1-\mathrm{C} 4$, fluorescence index, freshness index, humification index, $E_{2}: E_{3}, S_{275-295}$, $S_{350-400}$ and $S_{\mathrm{R}}$. To reach normal distribution of the DOM composition variables with fixed limits, $\mathrm{HMWS}_{\mathrm{C}}, \mathrm{HMWS}_{\mathrm{N}}$ and $\mathrm{HS}_{\mathrm{N}}$ were logit-transformed. Moreover, $\mathrm{C}: \mathrm{N}_{\text {bulk }}$ was log-transformed. Based on the approach described in Borcard et al. (2011), only variables that could be interpreted with high confidence were included in the interpretation of the PCA. We used the Scree test and Kaiser criterion to define the optimal number of PCA axes (Gotelli and Ellison, 2004). Prior to the PCA, all variables were centred and scaled (autoscaled) to get comparable scale levels (scale parameter, rda function, vegan package, R Core Team, 2015).

Based on the same variables as for PCA, the effects of country and farming type on DOM composition were tested using multivariate statistics: to assess whether differences in DOM composition between catchments were significant, permutative multivariate analyses of variance (PERMANOVA) were used (adonis function, vegan package, Oksanen et al., 2013) and to assess differences in their variability, permutative multivariate dispersal tests (PERMDISP) were used (betadisper and permutest.betadisper function, vegan package). Multivariate tests were based on Euclidean distances with independence of the replicates as the only assumption (Anderson, 2001). However, variable transformations from the PCA were kept to maximize comparability between the PCA plot and the statistical analyses. Prior to the PERMANOVAs/PERMDISPs, all variables were centred and scaled (autoscaled) to get comparable scale levels (scale function, stats package, R Core Team, 2015).

To assist in the interpretation of the effects of country and farming type on the DOM composition, Nemenyi tests (adapted oneway_test function, coin package, Hollander et al., 2013) of the effect of the sampled site on carbon or nitrogen in humic substances, $\mathrm{C}: \mathrm{N}$ ratio of humic substances, fluorescence index, PARAFAC component $\mathrm{C} 1$ and ratio of absorbance curve slopes ( $\mathrm{Sr}$ ) were conducted. 


\section{Results}

\subsection{Climate and discharge}

The Danish catchments were characterized by a colder climate than the Uruguayan catchments. The mean air temperature in the Danish catchments was $7.4^{\circ} \mathrm{C}\left( \pm \mathrm{SD}=6.9^{\circ} \mathrm{C}\right.$, $\left.\min =-11.8^{\circ} \mathrm{C}, \max =22.8^{\circ} \mathrm{C}\right)$. In the Uruguayan extensive farming catchment, the mean air temperature was $17.2^{\circ} \mathrm{C}\left( \pm \mathrm{SD}=6.5^{\circ} \mathrm{C}, \min =1.1^{\circ}, \max =32.1^{\circ} \mathrm{C}\right)$. In the Uruguayan intensive farming catchment, the mean air temperature was $16.5^{\circ} \mathrm{C}\left( \pm \mathrm{SD}=6.1^{\circ} \mathrm{C}\right.$, $\min =2.4^{\circ} \mathrm{C}$, $\max =30.5^{\circ} \mathrm{C}$ ).

Different precipitation patterns were observed in the different countries. In Denmark, the annual precipitation in 2011 was $735 \mathrm{~mm}$ for the extensive farming catchment and $745 \mathrm{~mm}$ for the intensive farming catchment. In Uruguay, the annual precipitation in 2011 was $901 \mathrm{~mm}$ for the extensive farming catchment and $1127 \mathrm{~mm}$ for the intensive farming catchment.

A clear difference in the temporal variability of the precipitation was observed between countries $(p<0.001$, Levene's test, $\left.n_{\text {Denmark }}=1640, n_{\text {Uruguay }}=1991\right)$, as $80 \%$ of the precipitation occurred in 6 and $8 \%$ of the sampled period in the intensive farming and extensive farming catchment in Uruguay, respectively. In contrast, $80 \%$ of the precipitation occurred in $20 \%$ of the sampled period in both the intensive farming and extensive farming catchment in Denmark (Fig. 1a). As can be seen from these results and the plot (Fig. 1a), the precipitation pattern was not significantly different between the intensive and extensive farming catchments in either Denmark or Uruguay ( $p>0.53$ for both Denmark and Uruguay, Levene's test, depending on the stream $n$ was 820-996).

Discharge differed significantly between catchments within countries, with the catchments in Uruguay exporting a larger volume of water within a shorter period of time than the catchments in Denmark $(p<0.001$, Levene's test, $n_{\text {Denmark }}=1554, n_{\text {Uruguay }}=1990$, Fig. $1 \mathrm{~b}$ ). In detail, $80 \%$ of discharge occurred in 9 and $20 \%$ of the sampled period in the intensive and extensive farming catchment in Uruguay, respectively (Fig. 1b). Moreover, $80 \%$ of discharge occurred in 43 and $73 \%$ of the sampled period in the intensive and extensive farming catchment in Denmark, respectively (Fig. 1b). The temporal variability of discharge was higher in the intensive than in the extensive farming catchments, both in Denmark and in Uruguay ( $p<0.001$, Levene's test, $n=777$ for each of the Danish streams and $n=995$ for each of the Uruguayan streams).

\subsection{DOC and DON concentrations and loads}

In Uruguay, DOC and DON concentrations were higher than in Denmark $(p<0.001$, permutative one-way tests, $n_{\text {Denmark }}=98, n_{\text {Uruguay }}=95$, Fig. 2$)$. The effect of inten-
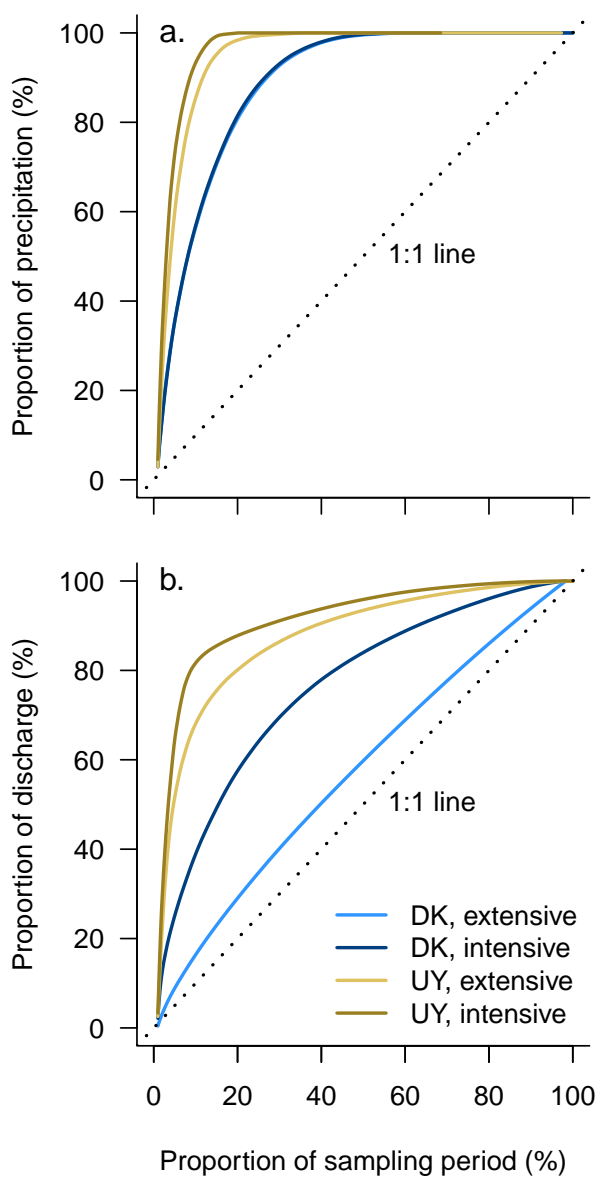

Figure 1. Ranked precipitation (a) and discharge values (b) versus the proportion of the sampling period. Precipitation data for both the intensive and extensive catchment in Denmark are included but are very similar. The $1: 1$ line represents a completely equal precipitation (a) or discharge (b) across the whole sampling period. Plot style adapted from Dalzell et al. (2007).

sive farming on DOC was only significant in Denmark ( $p<0.05$, Fig. $2 \mathrm{a}$ ), while intensive farming resulted in higher DON concentrations than extensive farming in both countries ( $p<0.05$, Nemenyi pairwise tests, $n$ was $47-49$, depending on the site, Fig. 2b),

The concentrations of DOC and DON were positively correlated with discharge for both Danish catchments (Spearman rank correlation, $\rho>0.63, p<0.001, n=48)$, but not for the Uruguayan catchments $(\rho<0.11, p>0.44$, $n_{\text {intensive }}=48, n_{\text {extensive }}=46$ ).

Loads of DOC and DON in the catchments with intensive farming were more temporally variable during the sampling period than in the catchments with extensive farming and were more variable in Uruguay than in Denmark (Fig. 2c and d). The highest temporal variability was found in the intensive farming catchment in Uruguay, in which more than $80 \%$ of the total DOC and DON load was exported in less than $10 \%$ of the sampled period (Fig. $2 \mathrm{c}$ and d). In contrast, 
Table 2. Loads of DOC and DON for the sampled catchments in 2011 and the median (range) daily loads for the whole sampling period. DK: Denmark, UY: Uruguay, extensive: extensive farming, intensive: intensive farming.

\begin{tabular}{lcrllc}
\hline Catchment & Annual DOC load & Annual DON load & & Daily DOC load & Daily DON load \\
\cline { 2 - 3 } \cline { 5 - 6 } & \multicolumn{2}{c}{$\mathrm{kg} \mathrm{km}^{-2} \mathrm{yr}^{-1}$} & & & Median (range) $\mathrm{kg} \mathrm{km}^{-2} \mathrm{~d}^{-1}$ \\
\hline DK, extensive & 2077.8 & 99.4 & & $5.0(31.0)$ & $0.24(1.8)$ \\
DK, intensive & 1267.9 & 75.2 & & $1.6(57.7)$ & $0.10(4.0)$ \\
UY, extensive & 1019.7 & 53.3 & & $1.2(93.7)$ & $0.06(4.6)$ \\
UY, intensive & 1824.5 & 105.2 & & $1.1(176.3)$ & $0.07(9.6)$ \\
\hline
\end{tabular}
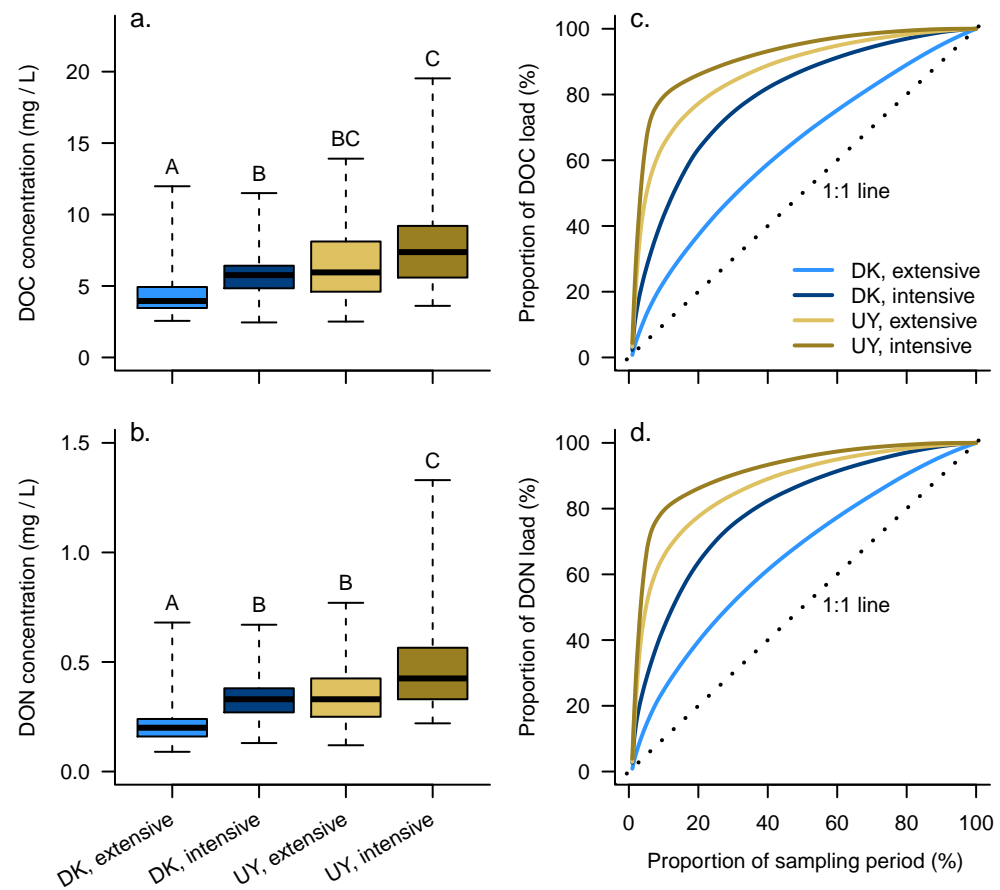

Figure 2. Concentrations (a, b) and ranked daily load versus the proportion of the sampling period (c and d, plot style adapted from Dalzell et al., 2007) for dissolved organic carbon (DOC) and dissolved organic nitrogen (DON). The $1: 1$ line in (c) and (d) represents a completely equal DOC and DON load across the whole sampling period. Capital letters indicate significantly different groups $(p<0.05$, Nemenyi pairwise test, $n$ was 47-49, depending on the stream). DK: Denmark, UY:Uruguay, extensive: extensive farming, intensive: intensive farming

$80 \%$ of the total DOC and DON load in the Danish extensive farming catchment was exported during $60 \%$ of the sampled period (Fig. 2c and d).

The temporal variability of DOC and DON loads was significantly different between countries $(p<0.001$, Levene's test, $\left.n_{\text {Denmark }}=1414, n_{\text {Uruguay }}=1455\right)$. Moreover, in Denmark, the farming type also had a significant effect on the temporal variability of DOC and DON loads $(p<0.001, n=707)$, while in Uruguay farming type only affected the temporal variability of DOC loads $\left(p=0.022, n_{\text {intensive }}=728, n_{\text {extensive }}=727\right)$ but not DON loads $(p=0.094)$.

Loads of DOC and DON were highly sensitive to changes in discharge (Spearman rank correlation, $\rho>0.92$, $n$ was 707-728, depending on the site) and to a lesser extent for the extensive farming catchment in Denmark $(\rho=0.53)$.
In contrast, the sensitivity of DOC and DON loads to changes in either DOC or DON concentration were low $(\rho<0.31)$, again except from the Danish extensive farming catchment (DOC: $\rho=0.74$, DON: $\rho=0.80$ ).

The annual DOC and DON load in 2011 was comparable between the study catchments, within the same order of magnitude and no effect of farming type or country could be observed (Table 2). The highest DOC load was found in the Danish extensive farming catchment, whereas the highest DON export was found in the Uruguayan intensive farming catchment (Table 2). The median daily loads of DOC and DON exhibited a different pattern as the annual loads for 2011, with the highest median DOC and DON loads always in the extensive farming catchment in Denmark (Table 2). Moreover, the range of DOC and DON loads was highest in 
the intensive farming catchment in Uruguay and lowest in the extensive farming catchment in Denmark (Table 2).

\subsection{Molecular DOM composition}

Table 3 shows the characteristics and interpretation of the PARAFAC components.

Country $\left(R^{2}=0.17, \quad p<0.001\right.$, PERMANOVA, $n$ was 47-49, depending on the site) and farming type $\left(R^{2}=0.13, p<0.001\right)$ had a significant effect on DOM composition and a significant interaction effect between country and farming type was found $\left(R^{2}=0.03, p<0.001\right)$. Furthermore, the effects of farming type were significant within each country $\left(p<0.001, R_{\text {Denmark }}^{2}=0.24\right.$, $R_{\text {Uruguay }}^{2}=0.14$, PERMANOVA).

Country had a significant effect on the temporal variability of DOM composition ( $p<0.001$, PERMDISP, $n$ was 47-49, depending on the site). The farming type within the countries had no significant effect on the temporal variability of DOM composition $(p>0.05)$.

Four PCA axes were selected to be optimally representing DOM composition ( $n=193$, number of variables $=20$ ). Together, these axes explained $73 \%$ of the total variance. The first and third PCA axes were positively correlated with the scores of the Danish catchments and negatively with the scores of the Uruguayan catchments (Fig. 3a and b). The second PCA axis separates farming types and was positively correlated with scores of the two catchments with extensive farming (Fig. 3a). The fourth PCA axis was neither correlated with country or farming type (Fig. 3b). The first PCA axis was positively correlated with $E_{2}: E_{3}, C 2$ and freshness index and negatively correlated with $C 3$, SUVA $_{\text {bulk }}$ and SUVA $_{\text {HS }}$ (Fig. 3a). The second PCA axis was positively correlated with $\mathrm{C}: \mathrm{N}_{\mathrm{HS}}, \mathrm{C}: \mathrm{N}_{\text {bulk }}, C 1$ and negatively correlated with HMWS $_{\mathrm{C}}$ and freshness index (Fig. 3a). The third PCA axis was positively correlated with $S_{350-400}$ and negatively correlated with $S_{275-295}$ and $S_{\mathrm{R}}$ (Fig. 3b). The fourth PCA axis was positively correlated with $\mathrm{HS}_{\mathrm{C}}$ and $\mathrm{HS}_{\mathrm{N}}$ and negatively correlated with $\mathrm{HMWS}_{\mathrm{N}}$ and $\mathrm{HMWS}_{\mathrm{C}}$ (Fig. 3b).

To get a better understanding of the changes in DOM composition, we investigated the absolute values of some DOM composition variables (Fig. 4). In all four catchments, DOC and DON consisted mainly of humic substances and no clear significant effect of country or farming type could be found here (Nemenyi test, $p>0.05, n$ was $47-49$, depending on the site, Fig. 4a and b). However, intensive farming resulted in lower $\mathrm{C}: \mathrm{N}_{\text {bulk }}(p<0.05)$, a higher fluorescence index and a lower $C 1$ in both Denmark and Uruguay (Fig. 4c and d). Moreover, $S_{\mathrm{R}}$ was significantly lower in Denmark than in Uruguay (Fig. 4e).
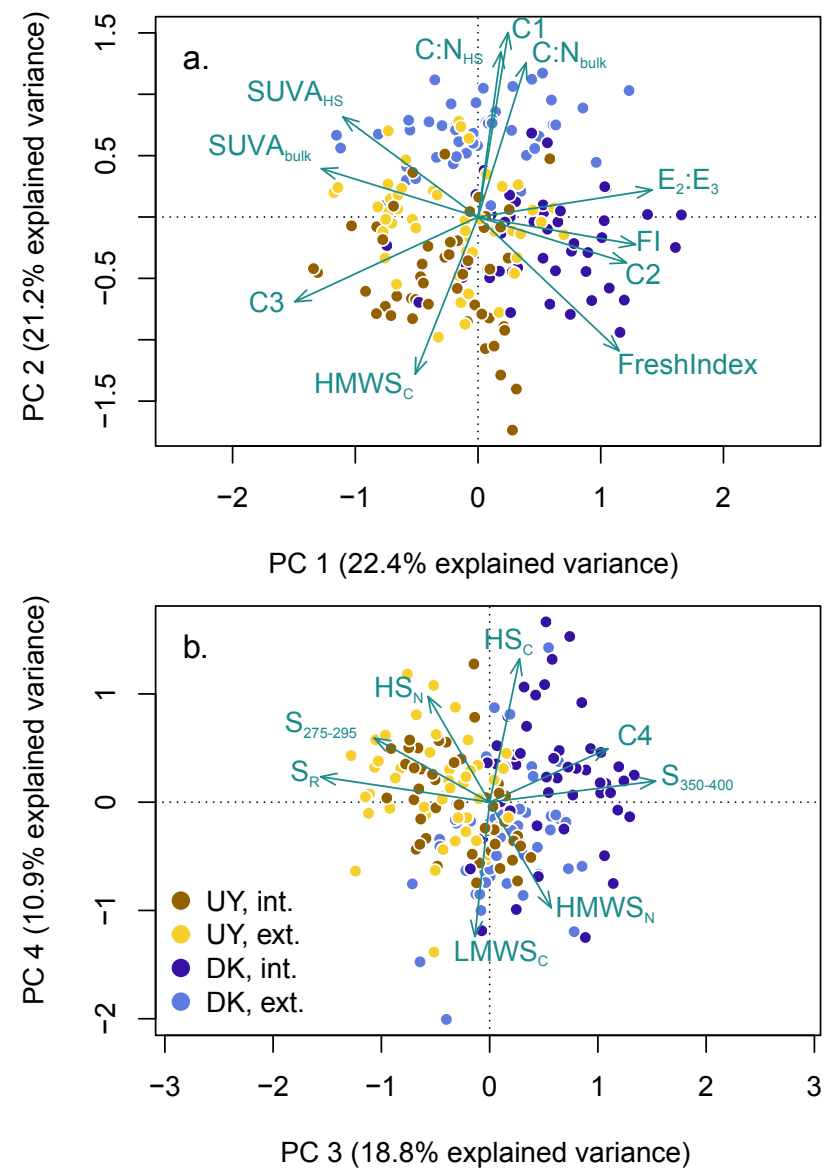

Figure 3. Principal component analysis (PCA) of dissolved organic matter (DOM) composition. The first four axes - PCA axis 1 and 2: (a), PCA axis 3 and 4: (b) - of the PCA explain $73 \%$ of the variance. Only those DOM composition variables are shown which can be interpreted with high confidence (Borcard et al., 2011). C1$C 4$ : fluorescence components 1 to 4 based on parallel factor analysis (see also Table 3); FI, fluorescence index; FreshIndex, freshness index; $E_{2}: E_{3}$, ratio of absorbance at $250 \mathrm{~nm}$ to absorbance at $365 \mathrm{~nm} ; S_{275-295}, S_{350-400}$ and $S_{\mathrm{R}}$, slope of absorbance at $275-285 \mathrm{~nm}, 350-400 \mathrm{~nm}$ and the ratio $(R)$ of these two slopes;

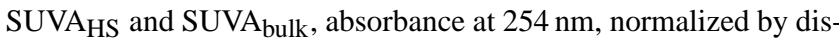
solved organic carbon concentration, for humic substances (HS) and all DOM fractions, respectively; $\mathrm{C}: \mathrm{N}_{\mathrm{HS}}$ and $\mathrm{C}: \mathrm{N}_{\text {bulk }}$, molar carbon to nitrogen ratio for $\mathrm{HS}$ and all DOM fractions, respectively; $\mathrm{HS}_{\mathrm{C}}$ and $\mathrm{HS}_{\mathrm{N}}, \mathrm{HMWS}_{\mathrm{C}}$ and $\mathrm{HMWS}_{\mathrm{N}}$ or $\mathrm{LMWS}_{\mathrm{C}}$, carbon $(\mathrm{C})$ and nitrogen $(\mathrm{N})$ in the humic substance (HS), highmolecular weight substance (HMWS) or low-molecular weight substance fraction (LMWS) based on size-exclusion chromatography. No values for LMWS $_{\mathrm{N}}$ exist, because N in LMWS is indistinguishable from N in nitrate. DK, Denmark; UY, Uruguay; extensive, extensive farming; intensive, intensive farming. 
Table 3. Excitation maxima (Ex., secondary maxima in parentheses), emission maximum (Em.) and tentative interpretation of fluorescence components based on parallel factor analysis (PARAFAC).

\begin{tabular}{|c|c|c|}
\hline Component & Definition (nm) & Tentative interpretation \\
\hline $\mathrm{C} 1$ & Ex.: $<240$ (385) Em.: 468 & $\begin{array}{l}\text { Terrestrial humic-like, found in freshwater environments (Murphy et al., 2011; } \\
\text { Yamashita et al., 2010b; Kowalczuk et al., 2009); relates to oxygen usage, mi- } \\
\text { crobial production and humification in marine systems (Stedmon and Mark- } \\
\text { ager, 2005b; Kowalczuk et al., 2013); removed by UV and visible light (Sted- } \\
\text { mon and Markager, 2005b) }\end{array}$ \\
\hline $\mathrm{C} 2$ & Ex.: $<240(300)$ Em.: 402 & $\begin{array}{l}\text { Microbial, humic-like, found in freshwater environments (Murphy et al., 2011; } \\
\text { Fellman et al., 2010; Stedmon and Markager, 2005a) potentially related to } \\
\text { algal, autochthonous sources (Søndergaard et al., 2003); related to terrestrial } \\
\text { sources in marine systems (Stedmon and Markager, 2005a; Stedmon et al., } \\
\text { 2007); removed by UV light (Stedmon et al., 2007) }\end{array}$ \\
\hline $\mathrm{C} 3$ & Ex.: 270 (415) Em.: 512 & $\begin{array}{l}\text { Fulvic-acid like, complex, ubiquitous fluorophore (Yamashita et al., 2010b, } \\
\text { a; Stedmon et al., 2007; Stedmon and Markager, 2005a); plant/soil-derived } \\
\text { semi-quinone like radical according to combined electron-spin resonance and } \\
\text { fluorescence measurements (Milori et al., 2002; Cory and McKnight, 2005); } \\
\text { similar component exported from wetlands and arable farming (Graeber et al., } \\
\text { 2012b) }\end{array}$ \\
\hline $\mathrm{C} 4$ & Ex.: 355 (255) Em.: 440 & $\begin{array}{l}\text { Humic-like, reduced-semiquinone character (Cory and McKnight, 2005); pos- } \\
\text { itively related to bacterial production (C4 in Williams et al., 2010); similar } \\
\text { component exported from arable farming catchments (Graeber et al., 2012b), } \\
\text { susceptible to chlorination (oxidation, Murphy et al., 2011) }\end{array}$ \\
\hline
\end{tabular}

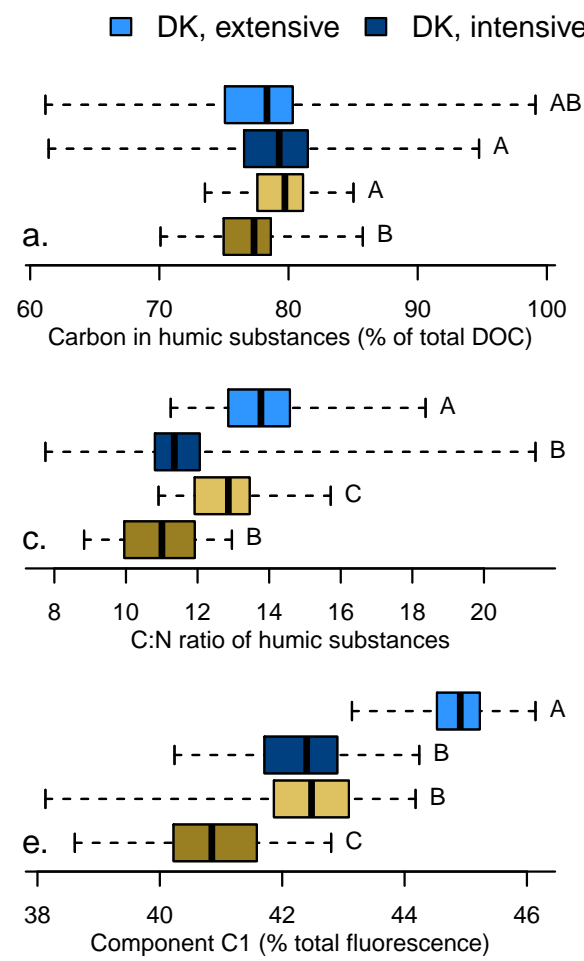

UY, extensive $\square$ UY, intensive

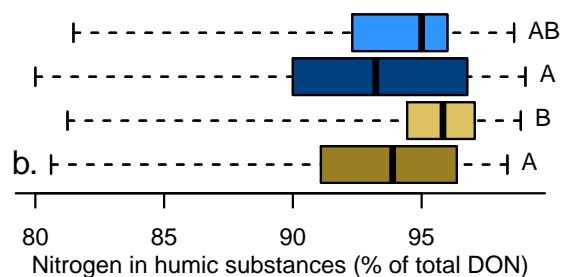

Nitrogen in humic substances (\% of total DON)
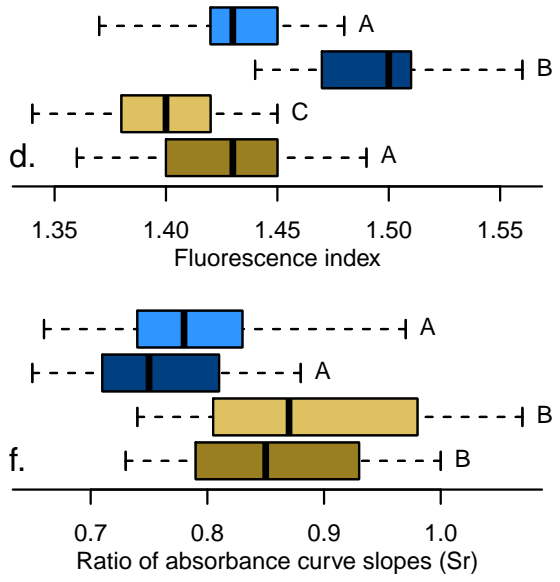

Figure 4. Selected variables of dissolved organic matter composition (DOM). Capital letters indicate significantly different groups $(p<0.05$, Nemenyi pairwise test, $n$ was 47-49, depending on the stream). DK, Denmark; UY, Uruguay; extensive, extensive farming; intensive, intensive farming. 


\section{Discussion}

In this study, we show that the combination of SEC and spectroscopic measurements allows great insight into the effects of agriculture on DOM export to freshwater systems. We could partly support our first hypothesis, since variability of DOC and DON loads was higher in Uruguay than in Denmark, but the size of annual DOC and DON loads was comparable between both countries. Our second hypothesis of a strong effect of climate on DOM composition was confirmed. However, contrary to the idea of higher microbial processing in Uruguay, several DOM composition indices pointed to a predominantly plant-derived DOM in Uruguay and a predominantly microbial-derived DOM in Denmark. Our third hypothesis of higher DOC and DON concentrations and higher temporal variability of DOC and DON loads in intensive farming could only partly be confirmed. In the two intensive farming catchments, DON, but not DOC concentrations were higher than in the extensive farming catchments within the same country. In contrast, we found a higher temporal variability of DOC and DON loads in the intensive farming catchments in both countries. Finally, we could clearly support our fourth hypothesis that DOM composition was affected similarly by intensive farming relative to extensive farming across climates and the direction of the changes in DOM composition strongly suggests that the management practices in intensive farming (fertilization, soil tillage) could be responsible for these changes.

\subsection{Differences of climate and discharge between the catchments}

Distinct climatic patterns differentiated Denmark from Uruguay. Uruguay was characterized by higher temperatures, as well as higher and more temporally variable precipitation. Within the two countries, temperature and precipitation, as well as its temporal variability only varied to a small degree between catchments.

Discharge was significantly more temporally variable in Uruguay than in Denmark. In addition to the higher temporal variability of precipitation, this reflects a lower buffer capacity for precipitation events in the Uruguayan catchments. The reasons are likely linked to the transport of water through shallow groundwater pathways or overland flow. In contrast, the Danish catchments had a higher buffering capacity for water from precipitation and were likely more dominated by groundwater discharge.

In both countries, the temporal variability of discharges significantly more different between intensive and extensive farming than could be expected solely on the basis of precipitation patterns. Furthermore, the difference was more pronounced in Denmark than in Uruguay. The reason for the higher difference of the temporal variability of discharges between the Danish catchments than the Uruguayan catchments was likely due to the tile drainage in the Danish intensive farming catchment. This resulted in a hydrological shortcut and a much faster and stronger response of discharge to precipitation events in the Danish intensive farming catchment than in the Danish extensive farming catchment (Dalzell et al., 2007). The Uruguayan intensive farming catchment was not artificially drained and the reasons for its higher temporal variability of discharge relative to the Uruguayan extensive farming catchment remain unclear. However, it is likely that the removal of buffer zones along the streams in the intensive agricultural areas in the Uruguayan intensive farming catchment lowered the buffer capacity of the soils for water from precipitation events and resulted in a faster response of discharge to rainfall events.

\subsection{Effects of climate on fluvial DOM quantity}

Discharge was an important driver of DOC and DON concentrations and loads in the Danish catchments. In contrast, DOC and DON loads but not concentrations were dependent on discharge in Uruguay.

Moreover, according to the sensitivity analysis of the load calculations, the temporal variability of DOC and DON loads of both catchments in Uruguay correlated well with discharge variability, but not with temporal variability of DOC or DON concentrations. We also found a high sensitivity of the DOC and DON loads to the temporal variability of the discharge in the Danish intensive farming catchment. However, the temporal variability of DOC and DON loads was lower in this catchment than in the Uruguayan catchments, since the temporal variability of discharges was lower. The only catchment in which the temporal variability of the loads was not primarily affected by the temporal variability of discharges was the Danish extensive farming catchment, for which the DOC and DON concentration had a stronger effect on DOC and DON loads than the discharge. The reason is likely the low discharge variability in this catchment, which resulted in larger importance of DOC and DON concentrations for DOC and DON loads.

Different patterns of precipitation were the ultimate driver for the differences of the temporal variability of DOC and DON loads across climates. The more variable precipitation in Uruguay resulted in a more variable discharge and with that, more variable DOC and DON loads. In addition, the more variable discharge also affected the DOC and DON concentrations in Denmark, which further increased the temporal variability of DOC and DON loads.

\subsection{Effects of climate on fluvial DOM quality}

In accordance with our second hypothesis, we found that climate had a strong effect on DOM composition. However, based on the PCA and in contrast to our hypothesis, the Uruguayan catchments were characterized by rather plantderived DOM relative to the Danish catchments: this notion was implied by higher percentages of $C 3$ and lower percent- 
ages of $C 2$ and $C 4$, together indicating DOM of plant origin (Søndergaard et al., 2003; Cory and McKnight, 2005), higher SUVA bulk $_{\text {and }}$ SUVA $_{\mathrm{HS}}$, both indicating higher aromaticity (Weishaar et al., 2003), lower $E_{2}: E_{3}$, indicating higher molecular weight (Peuravuori and Pihlaja, 2004), as well as higher $S_{275-295}, S_{\mathrm{r}}$ and lower $S_{350-400}$, together indicating DOM not yet processed by microbial organisms (Helms et al., 2008).

Altogether, fluvial DOM in Uruguay was to be likely derived from plant sources and was probably less microbially processed than in Denmark. This implies a lower soil and/or stream microbial activity in the Uruguayan than in the Danish catchments, which is surprising due to the higher temperatures in Uruguay. One explanation could be that in Uruguay the microbial processing of DOM from agricultural catchments is still limited by nutrient levels, whereas in Denmark, the long history of nutrient pollution (Kronvang et al., 2005) resulted in higher overall nutrient levels in the environment, facilitating higher levels of microbial processing. Another explanation could be the high temporal variability of precipitation and discharge in the Uruguayan catchments. Here, plant-derived organic matter which was stored in the upper soil layers could have been degraded during the long periods without precipitation and could be flushed out during high flow events. Based on this mechanism, one would expect a more variable DOM composition in Uruguay than in Denmark, since the DOM in Uruguay should be dominated by microbial sources during low flow and plant sources during high flow. In fact, a larger multivariate dispersal of DOM composition was found for the Uruguayan catchments in comparison to the Danish catchments. However, based only on in-stream measurements, we cannot infer the mechanisms behind the differences of DOM composition in the two climates. Here, additional comparative studies of the catchment sources in different climate zones would greatly advance the understanding of the mechanisms behind DOM export from catchments in different climates.

\subsection{Effects of farming intensity on fluvial DOM quantity}

The lack of clear effects of intensive arable farming on DOC concentration suggests that the effects of agriculture are depending on the history of land use and the current status of soil organic matter in the catchment (Stanley et al., 2012) and contradicts the notion of a general effect of intensive agriculture on DOC concentrations for regions outside the northern temperate climate zone (Graeber et al., 2012b; Heinz et al., 2015).

In contrast, the clear effect of intensive farming on DON concentrations in both countries could indicate a general effect of intensive agriculture, and is supported by studies in agricultural soils (van Kessel et al., 2009). However, no such clear effect of agriculture was found in the past in catchment-scale studies on DON concentrations in streams
(Willett et al., 2004; Stanley and Maxted, 2008). The disparity of results between soil and catchment-scale studies on the effects of agriculture on DON concentrations may be a result of DON measurement problems, as was clearly stated in some soil DON studies (Siemens and Kaupenjohann, 2002; Solinger et al., 2001). In detail, the indirect determination of DON as the difference between total dissolved nitrogen and dissolved inorganic nitrogen can result in severe miscalculations of DON concentrations in high-nitrate environments (Graeber et al., 2012a; Lee and Westerhoff, 2005; Vandenbruwane et al., 2007). Therefore, we propose that the differences in results between soil and stream studies are an artefact of the indirect determination of DON. This is supported by the strong increase of fluvial DON concentrations in catchments with intensive agriculture, which was found in a recent study when using the direct measurement of DON concentrations with SEC (Heinz et al., 2015). We recommend the use of the novel direct measurement technique shown in this and other studies (Graeber et al., 2012a; Heinz et al., 2015), or that treatments to remove nitrate and ammonium before indirect determination of DON (Lee and Westerhoff, 2005; Vandenbruwane et al., 2007; Chon et al., 2013; Graeber et al., 2012c) should be used in future studies to re-assess the effects of agriculture on DON concentrations in soils and in streams.

In contrast to the differences in the temporal variability of DOC and DON loads between the countries, precipitation was not the dominant driver of the differences in DOC and DON loads between intensive and extensive farming catchments within Denmark and Uruguay. The reason is that the precipitation patterns were highly similar within countries and even completely overlapping for the Danish catchments, whereas the discharges, and with that DOC and DON loads, mostly showed significant differences between the catchments within a country. Here, factors which were affecting discharges were also likely to affect DOC and DON loads: as described above, the subsurface tile drainage in the Danish intensive farming catchment (Dalzell et al., 2007) and the removal of buffer zones for intensive farming in Uruguay may have been responsible for the higher temporal variability of discharges which then resulted in higher temporal variability of DOC and DON loads.

The high temporal variability of DOC and DON loads in intensive farming catchments is in accordance to earlier studies on DOC loads, which were conducted in the mid-western USA (Dalzell et al., 2007; Royer and David, 2005). However, this effect has only once before been shown for DON loads in temperate catchments (Heinz et al., 2015). A higher temporal variability of DOC and DON loads has effects on the biogeochemistry of the downstream aquatic ecosystems, where the different availability of DOC and DON over time could affect the variability of connected ecosystem functions such as primary production, respiration and denitrification (Prairie, 2008; Berman and Bronk, 2003). 


\subsection{Effects of farming intensity on fluvial DOM quality}

In our study, DOM composition was strongly and similarly affected by the type of farming intensity in the two countries, which clearly supports our fourth hypothesis. We found an interaction effect between country and type of farming; however, this effect explained much less variance than the effect of farming type.

The similarity of the effect of farming type across countries is supported by the PCA, which revealed on the second axis that in Uruguay and Denmark the effects of farming type resulted in a similar shift in DOM composition. This shift was characterized by lower $C: \mathrm{N}_{\text {bulk }}$, lower $\mathrm{C}: \mathrm{N}_{\mathrm{HS}}$, lower $C 1$, higher $\mathrm{HMWS}_{\mathrm{C}}$ and a higher freshness index for the intensive farming catchments and was slightly more pronounced for the Danish than for the Uruguayan catchments.

Low DOM C: $\mathrm{N}$ ratios have been related to higher DOM bioavailability and microbial sources of DOM $(\mathrm{C}: \mathrm{N}$ ratio around 5-10, Sun et al., 1997; Petrone et al., 2009) and thus DOM from intensive farming catchments with median $\mathrm{C}: \mathrm{N}$ ratios of 11 could indicate a shift in soil or in-stream DOM sources and could be of higher biogeochemical activity than DOM from extensive farming catchments (Heinz et al., 2015). Interestingly, the $C: N$ ratios of the relatively complex humic substances $\left(\mathrm{C}: \mathrm{N}_{\mathrm{HS}}\right)$ were also lower in the intensive farming catchments. In soils, DOM C: $\mathrm{N}$ ratios as in our study are only found in deeper layers as a result of heavy microbial processing (Kaiser and Kalbitz, 2012) and high DOM complexity similar to ours is typically found for DOM released from soil organic matter (Schmidt et al., 2011). Thus, the complex, humic fluvial DOM with low $\mathrm{C}: \mathrm{N}$ ratios in catchments with intensive farming is a strong indication of microbial sources in deeper soil layers (Heinz et al., 2015).

The other variables of DOM composition also support the notion of microbially produced DOM: in the PCA, the intensive farming catchments and $\mathrm{HMWS}_{\mathrm{C}}$ were positively correlated, which indicates rather microbial sources. Highmolecular weight substances were found to be released by extracellular polymeric substances of biofilms (Stewart et al., 2013) and in another study of temperate catchments, the same effect of intensive agriculture on fluvial $\mathrm{HMWS}_{\mathrm{C}}$ was found (Heinz et al., 2015). Fluorescence index and freshness index were also higher in the intensive farming catchments, indicating a relatively recent, more microbial source of the humic fraction of DOM (Cory and McKnight, 2005; Parlanti et al., 2000), and the PARAFAC component $C 1$ was also positively correlated to intensive farming, which indicates higher oxygen usage and microbial production according to studies in marine waters (Stedmon and Markager, 2005b; Kowalczuk et al., 2013). In conclusion, fluvial DOM from intensive farming catchments is relatively complex, but of more microbial origin compared with fluvial DOM from extensive farming catchments in both Denmark and Uruguay. Similar effects of intensive farming on DOM in streams were shown for temperate agricultural catchments (Williams et al.,
2010; Wilson and Xenopoulos, 2009; Graeber et al., 2012b) but never before in a comparison between different climates. Moreover, the high similarity of the effect of intensive farming on DOM in Denmark and Uruguay implies that the same mechanism is responsible for the changes in fluvial DOM composition in intensive farming catchments in different climatic zones.

Our results strongly imply microbial processing in deeper soil layers as being the source for the DOM in intensive farming. Several typical agricultural management practices may have been responsible for this pattern, either solely or in interaction. Soil tillage breaks up soil organic matter (SOM) aggregates and can result in strong microbial processing of SOM within these aggregates (Ewing et al., 2006). This may result in release of aged DOM previously bound to such SOM to freshwater ecosystems and, in fact, a high age of fluvial DOC was found in a study of US agricultural catchments (Sickman et al., 2010). Furthermore, nitrogen and phosphorus fertilizer addition to soils in intensive farming may promote higher microbial activity and result in higher release of DOM from SOM. However, extrapolation of the effects of intensive farming on DOM composition in other intensively farmed catchments, as well as the understanding of the mechanisms responsible for these effects remain speculative and should be tested by additional studies.

\section{Conclusions}

This study found distinct effects of climate on fluvial DOM, thus supporting earlier findings that climate is the main driver of DOM export from catchments. However, this is the first study to test the effect of climate on DOM quality. We found strong differences in DOM quality between the catchments in the two investigated climatic zones but cannot clearly attribute this to either climatic or soil factors. Further studies of DOM sources in the catchments are needed to get a clearer picture of why these differences between different climatic regions are found.

We have shown that fluvial DOM from intensive farming is complex and of microbial origin and that effects of intensive farming on DOM composition superimpose effects of climate or soil which may act in the two investigated regions. Moreover, intensive farming was strongly linked to a high temporal variability of the export of DOC and DON to freshwater ecosystems, which may affect the predicability of ecosystem processes fuelled by DOC and DON. The effects of intensive farming on DOM composition agree with recent findings from other studies in temperate climate and imply general mechanisms, by which intensive farming impacts the composition of DOM in streams. Based on the composition of fluvial DOM, we find it likely that this mechanism is linked to the management of agricultural soils and that intensive farming may affect DOM in aquatic ecosystems, as 
well as linked ecosystem processes and biogeochemical cycles globally.

The effects of agriculture on DOM could only accurately be assessed by a combination of novel monitoring techniques, which combine direct measurements of DOC and DON with an analysis of spectroscopic DOM composition. Future DOM monitoring programmes should include similar techniques, if the effects of human activities on DOM are to be accurately evaluated. 


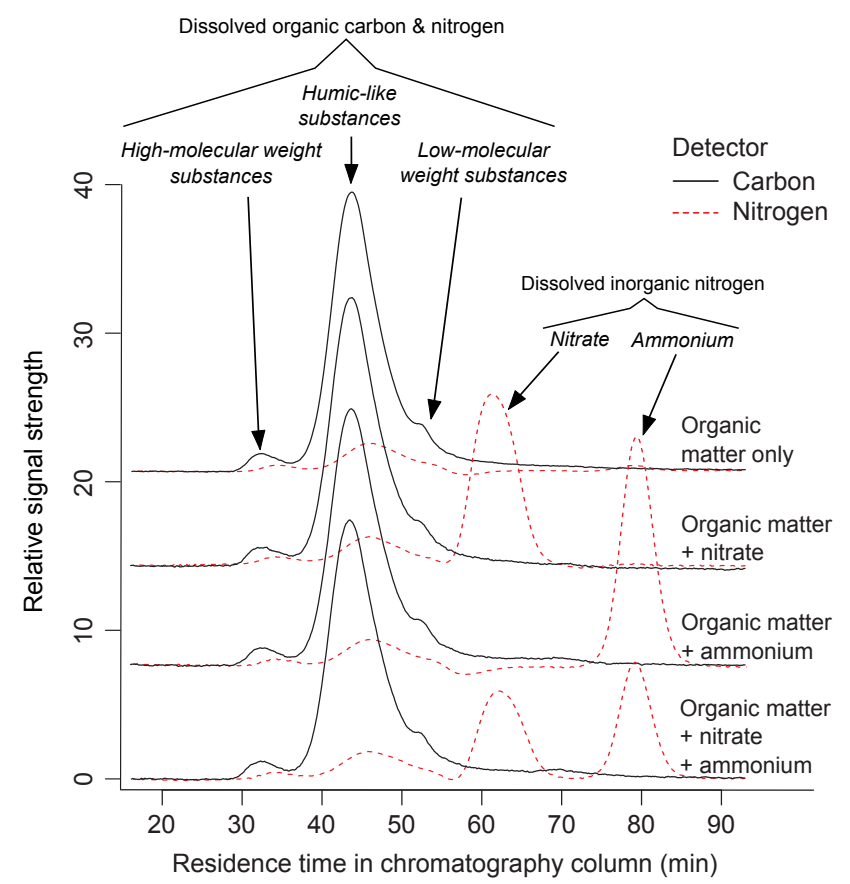

Figure A1. Typical chromatogram of size-exclusion chromatography to show the distribution of DOM fractions with and without added nitrate and ammonium. The sample for this chromatogram was taken at a wetland outflow in Brandenburg, Germany.

\section{Appendix A: Typical chromatogram with the fractions of DOC and DON}

In Fig. A1 a typical chromatogram of a DOM sample is shown. Several treatments with and without nitrate and ammonium are shown to give an idea of the separation of DON, nitrate and ammonium, which allows the direct DON measurement. Please see Graeber et al. (2012b) for further comparisons of the indirect and direct determination of DON. 
Appendix B: Split-half validation of the PARAFAC model

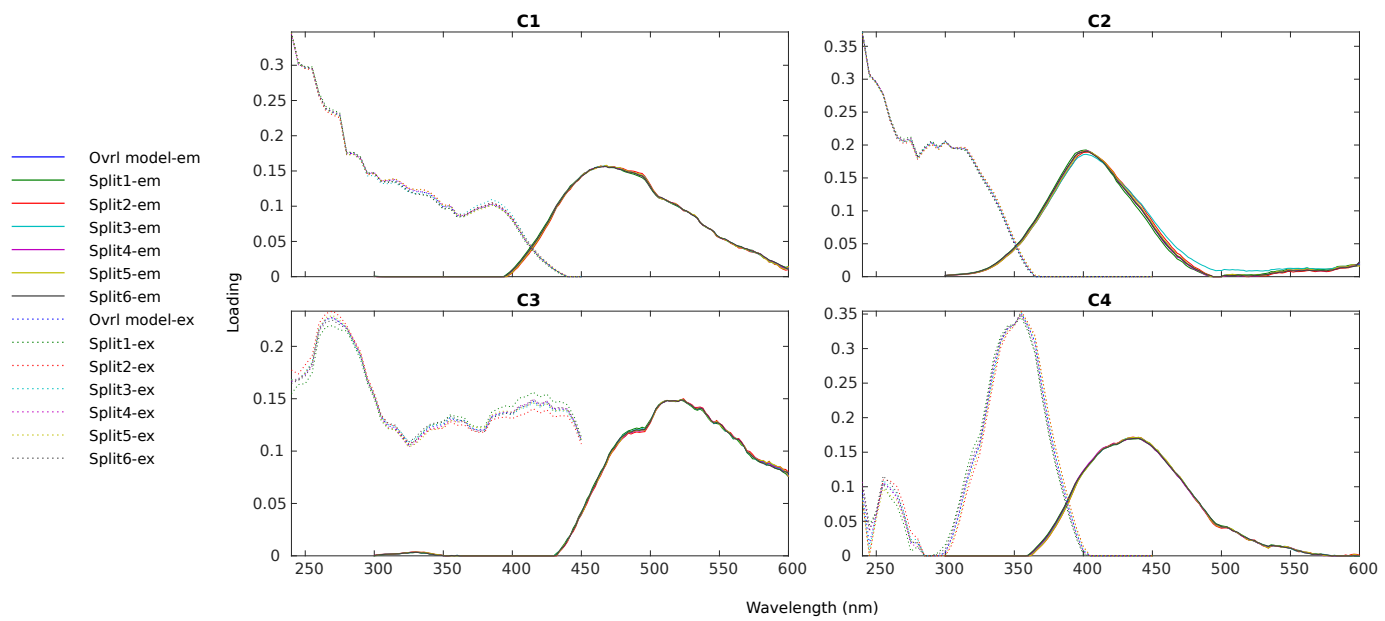

Figure B1. Split-half validation of the PARAFAC model. The models for six halves generated by the standard method described in Murphy et al. (2013) are shown. When the fits of the splits are similar to each other and the entire model, a high stability of the model and low randomness of the fluorophores is given.

The split-half validation proved that the number of components is stable even for subsets of the data set (Fig. B1). This is one of the main criteria when validating the number of components for a data set (please see Murphy et al., 2013, for further details on the validation steps). 
Acknowledgements. We thank Marlene Venø Skjærbæk from Aarhus University for her assistance in the field and in the laboratory. Moreover, we thank Sarah Schell and Claudia Theel from Leibniz-Institute of Freshwater Ecology and Inland Fisheries for their assistance in the laboratory. The study was funded by the ECOGLOBE project (Danish Council for Independent Research, Natural Sciences, 09-067335).

Edited by: F. van Geer

\section{References}

Aitkenhead, J. and McDowell, W.: Soil C : N ratio as a predictor of annual riverine DOC flux at local and global scales, Global Biogeochem. Cy., 14, 127-138, doi:10.1029/1999GB900083, 2000.

Anderson, M.: A new method for non-parametric multivariate analysis of variance, Aust. Ecol., 26, 32-46, doi:10.1111/j.14429993.2001.01070.pp.x, 2001.

Balesdent, J., Chenu, C., and Balabane, M.: Relationship of soil organic matter dynamics to physical protection and tillage, Soil Till. Res., 53, 215-230, doi:10.1016/S0167-1987(99)00107-5, 2000.

Berman, T. and Bronk, D.: Dissolved organic nitrogen: a dynamic participant in aquatic ecosystems, Aquat. Microb. Ecol., 31, 279305, doi:10.3354/ame031279, 2003.

Borcard, D., Gillet, F., and Legendre, P.: Numerical ecology with R, Springer Verlag, Heidelberg, 2011.

Chon, K., Lee, Y., Traber, J., and von Gunten, U.: Quantification and characterization of dissolved organic nitrogen in wastewater effluents by electrodialysis treatment followed by size-exclusion chromatography with nitrogen detection, Water Res., 47, 53815391, doi:10.1016/j.watres.2013.06.019, 2013.

Cory, R. and McKnight, D.: Fluorescence Spectroscopy Reveals Ubiquitous Presence of Oxidized and Reduced Quinones in Dissolved Organic Matter, Environ. Sci. Technol., 39, 8142-8149, doi:10.1021/es0506962, 2005.

Dalzell, B. J., Filley, T. R., and Harbor, J. M.: The role of hydrology in annual organic carbon loads and terrestrial organic matter export from a midwestern agricultural watershed, Geochim. Cosmochim. Acta, 71, 1448-1462, doi:10.1016/j.gca.2006.12.009, 2007.

European Commission and European Soil Bureau Network: The European Soil Database distribution version 2.0, Tech. rep., European comission, http://eusoils.jrc.ec.europa.eu/ESDB_ Archive/ESDB_Data_Distribution/ESDB_data.html (last access: 14 November 2011), 2004.

Ewing, S. A., Sanderman, J., Baisden, W., Wang, Y., and Amundson, R.: Role of large-scale soil structure in organic carbon turnover: evidence from California grassland soils, J. Geophys. Res.-Biogeo., 111, G03012-G03012, doi:10.1029/2006JG000174, 2006.

Fellman, J., Hood, E., and Spencer, R.: Fluorescence spectroscopy opens new windows into dissolved organic matter dynamics in freshwater ecosystems: a review, Limnol. Oceanogr., 55, 24522462, doi:10.4319/lo.2010.55.6.2452, 2010.

Fellman, J. B., Petrone, K. C., and Grierson, P. F.: Source, biogeochemical cycling, and fluorescence characteristics of dissolved organic matter in an agro-urban estuary RID B-1345-2011, Lim- nol. Oceanogr., 56, 243-256, doi:10.4319/lo.2011.56.1.0243, 2011.

Fox, J. and Weisberg, S.: An R Companion to Applied Regression, Sage, Thousand Oaks CA, 2nd Edn., http://socserv. socsci.mcmaster.ca/jfox/Books/Companion (last access: 30 January 2015), 2011.

Gotelli, N. J. and Ellison, A. M.: A primer of ecological statistics, vol. 1, Palgrave Macmillan, Hants, UK, 2004.

Goyenola, G., Meerhoff, M., Teixeira-de Mello, F., GonzálezBergonzoni, I., Graeber, D., Fosalba, C., Vidal, N., Mazzeo, N., Ovesen, N. B., Jeppesen, E., and Kronvang, B.: Phosphorus dynamics in lowland streams as a response to climatic, hydrological and agricultural land use gradients, Hydrol. Earth Syst. Sci. Discuss., 12, 3349-3390, doi:10.5194/hessd-12-3349-2015, 2015.

Graeber, D., Gelbrecht, J., Kronvang, B., Gücker, B., Pusch, M. T., and Zwirnmann, E.: Technical Note: Comparison between a direct and the standard, indirect method for dissolved organic nitrogen determination in freshwater environments with high dissolved inorganic nitrogen concentrations, Biogeosciences, 9, 4873-4884, doi:10.5194/bg-9-4873-2012, 2012a.

Graeber, D., Gelbrecht, J., Pusch, M., Anlanger, C., and von Schiller, D.: Agriculture has changed the amount and composition of dissolved organic matter in Central European headwater streams, Sci. Total Environ., 438, 435-446, doi:10.1016/j.scitotenv.2012.08.087, 2012b.

Graeber, D., Gücker, B., Zwirnmann, E., Kronvang, B., Weih, C., and Gelbrecht, J.: Dialysis is superior to anion exchange for removal of dissolved inorganic nitrogen from freshwater samples prior to dissolved organic nitrogen determination, Environ. Chem., 9, 529-536, doi:10.1071/EN11170, 2012c.

Green, S. and Blough, N.: Optical absorption and fluorescence properties of chromophoric dissolved organic matter in natural waters, Limnol. Oceanogr., 39, 1903-1916, doi:10.4319/lo.1994.39.8.1903, 1994.

Heinz, M., Graeber, D., Zak, D., Zwirnmann, E., Gelbrecht, J., and Pusch, M.: Comparison of organic matter composition in agricultural versus forest affected headwaters with special emphasis on organic nitrogen, Environ. Sci. Technol., 49, 2081-2090, doi:10.1021/es505146h, 2015.

Helms, J., Stubbins, A., Ritchie, J., Minor, E., Kieber, D., and Mopper, K.: Absorption spectral slopes and slope ratios as indicators of molecular weight, source, and photobleaching of chromophoric dissolved organic matter, Limnol. Oceanogr., 53, 955969, doi:10.4319/lo.2008.53.3.0955, 2008.

Hollander, M., Wolfe, D. A., and Chicken, E.: Nonparametric statistical methods, vol. 751, John Wiley \& Sons, Weinheim, 2013.

Hothorn, T., Hornik, K., Van De Wiel, M. A., and Zeileis, A.: A lego system for conditional inference, Am. Stat., 60, 257-263, doi:10.1198/000313006X118430, 2006.

Huber, S., Balz, A., Abert, M., and Pronk, W.: Characterisation of aquatic humic and non-humic matter with size-exclusion chromatography - organic carbon detection - organic nitrogen detection (LC-OCD-OND), Water Res., 45, 879-885, doi:10.1016/j.watres.2010.09.023, 2011.

Hudson, N., Baker, A., Reynolds, D., Carliell-Marquet, C., and Ward, D.: Changes in freshwater organic matter fluorescence intensity with freezing/ thawing and dehydration/ rehydration., J. Geophys. Res.-Biogeo., 114, G00F08, doi:10.1029/2008JG000915, 2009. 
Kaiser, K. and Kalbitz, K.: Cycling downwards-dissolved organic matter in soils, Soil Biol. Biochem., 52, 29-32, doi:10.1016/j.soilbio.2012.04.002, 2012.

Kauppila, P. and Koskiaho, J.: Evaluation of annual loads of nutrients and suspended solids in Baltic rivers, Nord. Hydrol., 34, 203-220, 2003.

Kothawala, D. N., Murphy, K. R., Stedmon, C. A., Weyhenmeyer, G. A., and Tranvik, L. J.: Inner filter correction of dissolved organic matter fluorescence, Limnol. Oceanogr-Meth., 11, 616630, doi:10.4319/lom.2013.11.616, 2013.

Kowalczuk, P., Durako, M. J., Young, H., Kahn, A. E., Cooper, W. J., and Gonsior, M.: Characterization of dissolved organic matter fluorescence in the South Atlantic Bight with use of PARAFAC model: Interannual variability, Mar. Chem., 113, 182-196, doi:10.1016/j.marchem.2009.01.015, 2009.

Kowalczuk, P., Tilstone, G. H., Zabłocka, M., Röttgers, R., and Thomas, R.: Composition of dissolved organic matter along an Atlantic Meridional Transect from fluorescence spectroscopy and Parallel Factor Analysis, Mar. Chem., 157, 170-184, doi:10.1016/j.marchem.2013.10.004, 2013.

Kronvang, B., Jeppesen, E., Conley, D., Sondergaard, M., Larsen, S., Ovesen, N., and Carstensen, J.: Nutrient pressures and ecological responses to nutrient loading reductions in Danish streams, lakes and coastal waters, J. Hydrol., 304, 274-288, doi:10.1016/j.jhydrol.2004.07.035, 2005.

Lawaetz, A. and Stedmon, C.: Fluorescence intensity calibration using the Raman scatter peak of water, Appl. Spectrosc., 63, 936940, doi:10.1366/000370209788964548, 2009.

Lee, W. and Westerhoff, P.: Dissolved organic nitrogen measurement using dialysis pretreatment, Environ. Sci. Technol., 39, 879-884, doi:10.1021/es048818y, 2005.

Milori, D. M., Martin-Neto, L., Bayer, C., Mielniczuk, J., and Bagnato, V. S.: Humification degree of soil humic acids determined by fluorescence spectroscopy, Soil Sci., 167, 739-749, doi:10.1097/00010694-200211000-00004, 2002.

Mulholland, P.: Dissolved organic matter concentration and flux in streams, J. N. Am. Benthol. Soc., 16, 131-141, doi:10.2307/1468246, 1997.

Murphy, K. R., Hambly, A., Singh, S., Henderson, R. K., Baker, A., Stuetz, R., and Khan, S. J.: Organic matter fluorescence in municipal water recycling schemes: toward a unified PARAFAC model, Environ. Sci. Technol., 45, 2909-2916, doi:10.1021/es103015e, 2011.

Murphy, K. R., Stedmon, C. A., Graeber, D., and Bro, R.: Fluorescence spectroscopy and multi-way techniques: PARAFAC, Anal. Meth., 5, 6557-6566, doi:10.1039/C3AY41160E, 2013.

Murphy, K. R., Stedmon, C. A., Wenig, P., and Bro, R.: OpenFluor - an online spectral library of auto-fluorescence by organic compounds in the environment, Anal. Meth., 6, 658-661, doi:10.1039/C3AY41935E, 2014.

Nimptsch, J., Woelfl, S., Kronvang, B., Giesecke, R., González, H. E., Caputo, L., Gelbrecht, J. G., von Tuempling, W., and Graeber, D.: Does filter type and pore size influence spectroscopic analysis of freshwater chromophoric DOM composition?, Limnol. Ecol. Manage. Inl. Waters, 48, 57-64, doi:10.1016/j.limno.2014.06.003, 2014.

Ohno, T.: Fluorescence inner-filtering correction for determining the humification index of dissolved organic matter, Environ. Sci. Technol., 36, 742-746, doi:10.1021/es0155276, 2002.
Ohno, T. and Bro, R.: Dissolved organic matter characterization using multiway spectral decomposition of fluorescence landscapes, Soil Sci. Soc. Am. J., 70, 2028-2037, doi:10.2136/sssaj2006.0005, 2006.

Oksanen, J., Blanchet, F. G., Kindt, R., Legendre, P., Minchin, P. R., O'Hara, R. B., Simpson, G. L., Solymos, P., Stevens, M. H. H., and Wagner, H.: vegan: Community Ecology Package, r package version 2.0-7, http://CRAN.R-project.org/package=vegan (last access: 13 May 2015), 2013.

Parlanti, E., Worz, K., Geoffroy, L., and Lamotte, M.: Dissolved organic matter fluorescence spectroscopy as a tool to estimate biological activity in a coastal zone submitted to anthropogenic inputs, Org. Geochem., 31, 1765-1781, doi:10.1016/S01466380(00)00124-8, 2000.

Patel-Sorrentino, N., Mounier, S., and Benaim, J.: Excitationemission fluorescence matrix to study $\mathrm{pH}$ influence on organic matter fluorescence in the Amazon basin rivers, Water Res., 36, 2571-2581, doi:10.1016/S0043-1354(01)00469-9, 2002.

Petrone, K.: Catchment export of carbon, nitrogen, and phosphorus across an agro-urban land use gradient, Swan-Canning River system, southwestern Australia, J. Geophys. Res.-Biogeo., 115, G01016, doi:10.1007/s10533-008-9238-z, 2010.

Petrone, K., Richards, J., and Grierson, P.: Bioavailability and composition of dissolved organic carbon and nitrogen in a near coastal catchment of south-western Australia, Biogeochemistry, 92, 27-40, doi:10.1007/s10533-008-9238-z, 2009.

Peuravuori, J. and Pihlaja, K.: Preliminary study of lake dissolved organic matter in light of nanoscale supramolecular assembly, Environ. Sci. Technol., 38, 5958-5967, doi:10.1021/es0400411, 2004.

Pfeifer, D., Hoffmann, K., Hoffmann, A., Monte, C., and ReschGenger, U.: The kit spectral fluorescence standards - a simple calibration tool for the standardization of the spectral characteristics of fluorescence instruments, J. Fluoresc., 16, 581-587, doi:10.1007/s10895-006-0086-8, 2006.

Pouillot, R. and Delignette-Muller, M. L.: Evaluating variability and uncertainty separately in microbial quantitative risk assessment using two R packages, Int. J. Food Microbiol., 142, 330-340, doi:10.1016/j.ijfoodmicro.2010.07.011, 2010.

Prairie, Y. T.: Carbocentric limnology: Looking back, looking forward, Can. J. Fish. Aquat. Sci., 65, 543-548, doi:10.1139/f08011, 2008.

R Core Team: R: A Language and Environment for Statistical Computing, R Foundation for Statistical Computing, Vienna, Austria, http://www.R-project.org/, last access: 19 March 2015.

Royer, T. and David, M.: Export of dissolved organic carbon from agricultural streams in Illinois, USA, Aquat. Sci., 67, 465-471, doi:10.1007/s00027-005-0781-6, 2005.

Schmidt, M., Torn, M., Abiven, S., Dittmar, T., Guggenberger, G., Janssens, I., Kleber, M., Kögel-Knabner, I., Lehmann, J., Manning, D., Nannipieri, P., Rasse, D. P., Weiner, S., and Trumbore, S. E.: Persistence of soil organic matter as an ecosystem property, Nature, 478, 49-56, doi:10.1038/nature10386, 2011.

Sickman, J., DiGiorgio, C., Davisson, M., Lucero, D., and Bergamaschi, B.: Identifying sources of dissolved organic carbon in agriculturally dominated rivers using radiocarbon age dating: Sacramento-San Joaquin River Basin, California, Biogeochemistry, 99, 79-96, 2010. 
Siemens, J. and Kaupenjohann, M.: Contribution of dissolved organic nitrogen to $\mathrm{N}$ leaching from four German agricultural soils, J. Plant Nutr. Soil Sci., 165, 675-681, doi:10.1002/jpln.200290002, 2002.

Solinger, S., Kalbitz, K., and Matzner, E.: Controls on the dynamics of dissolved organic carbon and nitrogen in a Central European deciduous forest, Biogeochemistry, 55, 327-349, 2001.

Søndergaard, M., Stedmon, C., and Borch, N.: Fate of terrigenous dissolved organic matter (DOM) in estuaries: Aggregation and bioavailability, Ophelia, 57, 161-176, doi:10.1080/00785236.2003.10409512, 2003.

Stanley, E. H. and Maxted, J.: Changes in the dissolved nitrogen pool across land cover gradients in Wisconsin streams, Ecol. Appl., 18, 1579-1590, doi:10.1890/07-1379.1, 2008.

Stanley, E. H., Powers, S. M., Lottig, N. R., Buffam, I., and Crawford, J. T.: Contemporary changes in dissolved organic carbon (DOC) in human-dominated rivers: is there a role for DOC management?, Freshwater Biol., 57, 26-42, doi:10.1111/j.13652427.2011.02613.x, 2012.

Stedmon, C. and Markager, S.: Resolving the variability in dissolved organic matter fluorescence in a temperate estuary and its catchment using PARAFAC analysis, Limnol. Oceanogr., 50, 686-697, doi:10.4319/lo.2005.50.2.0686, 2005a.

Stedmon, C. and Markager, S.: Tracing the production and degradation of autochthonous fractions of dissolved organic matter by fluorescence analysis, Limnol. Oceanogr., 50, 1415-1426, doi:10.4319/lo.2005.50.5.1415, 2005 b.

Stedmon, C., Thomas, D., Granskog, M., Kaartokallio, H., Papadimitriou, S., and Kuosa, H.: Characteristics of dissolved organic matter in Baltic coastal sea ice: Allochthonous or autochthonous origins?, Environ. Sci. Technol., 41, 7273-7279, doi:10.1021/es071210f, 2007.

Stewart, T. J., Traber, J., Kroll, A., Behra, R., and Sigg, L.: Characterization of extracellular polymeric substances (EPS) from periphyton using liquid chromatography-organic carbon detectionorganic nitrogen detection (LC-OCD-OND), Environ. Sci. Pollut. R., 20, 3214-3223, doi:10.1007/s11356-012-1228-y, 2013.

Stubbins, A., Lapierre, J., Berggren, M., and Dittmar, T., and del Giorgio, P.: What's in an EEM? Molecular Signatures Associated with Dissolved Organic Fluorescence in Boreal Canada, Environ. Sci. Technol., 48, 10598-10606, doi:10.1021/es502086e, 2014.
Sun, L., Perdue, E., Meyer, J., and Weis, J.: Use of elemental composition to predict bioavailability of dissolved organic matter in a Georgia river, Limnol. Oceanogr., 42, 714-721, doi:10.4319/lo.1997.42.4.0714, 1997.

Vandenbruwane, J., De Neve, S., Qualls, R., Salomez, J., and Hofman, G.: Optimization of dissolved organic nitrogen (DON) measurements in aqueous samples with high inorganic nitrogen concentrations, Sci. Total Environ., 386, 103-113, doi:10.1016/j.scitotenv.2007.06.025, 2007.

van Kessel, C., Clough, T., and van Groenigen, J.: Dissolved organic nitrogen: an overlooked pathway of nitrogen loss from agricultural systems?, J. Environ. Qual., 38, 393-401, doi:10.2134/jeq2008.0277, 2009.

Weishaar, J., Aiken, G., Bergamaschi, B., Fram, M., Fujii, R., and Mopper, K.: Evaluation of specific ultraviolet absorbance as an indicator of the chemical composition and reactivity of dissolved organic carbon, Environ. Sci. Technol., 37, 4702-4708, doi:10.1021/es030360x, 2003.

Willett, V., Reynolds, B., Stevens, P., Ormerod, S., and Jones, D.: Dissolved organic nitrogen regulation in freshwaters, J. Environ. Qual., 33, 201-209, doi:10.2134/jeq2004.2010, 2004.

Williams, C., Yamashita, Y., Wilson, H., Jaffe, R., and Xenopoulos, M.: Unraveling the role of land use and microbial activity in shaping dissolved organic matter characteristics in stream ecosystems, Limnol. Oceanogr., 55, 1159-1171, doi:10.4319/lo.2010.55.3.1159, 2010.

Williams, M., Hopkinson, C., Rastetter, E., Vallino, J., and Claessens, L.: Relationships of land use and stream solute concentrations in the Ipswich River basin, northeastern Massachusetts, Water Air Soil Poll., 161, 55-74, doi:10.1007/s11270-005-2830-0, 2005.

Wilson, H. and Xenopoulos, M.: Effects of agricultural land use on the composition of fluvial dissolved organic matter, Nat. Geosci., 2, 37-41, doi:10.1038/ngeo391, 2009.

Yamashita, Y., Maie, N., Briceno, H., and Jaffé, R.: Optical characterization of dissolved organic matter in tropical rivers of the Guayana Shield, Venezuela, J. Geophys. Res.-Biogeo., 115, G00F10, doi:10.1029/2009JG000987, 2010a.

Yamashita, Y., Scinto, L. J., Maie, N., and Jaffé, R.: Dissolved Organic Matter Characteristics Across a Subtropical Wetland's Landscape: Application of Optical Properties in the Assessment of Environmental Dynamics, Ecosystems, 13, 1006-1019, doi:10.1007/s10021-010-9370-1, 2010b. 